\title{
The Axin2-snail axis promotes bone invasion by activating cancer-associated fibroblasts in oral squamous cell carcinoma
}

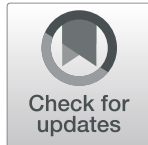

Yin-Zhe $\mathrm{An}^{1 \dagger}$, Eunae Cho ${ }^{2,3,4 \dagger}$, Junqi Ling ${ }^{1,5^{*}}$ and Xianglan Zhang ${ }^{4,6^{*}}$

\begin{abstract}
Background: In bone-invasive oral squamous cell carcinoma (OSCC), cancer-associated fibroblasts (CAFs) infiltrate into bony tissue ahead of OSCC cells. In the present study, we aimed to investigate the role of the Axin2-Snail axis in the biological behaviour of CAFs and bone invasion in OSCC.

Methods: The clinicopathological significance of Axin2 and Snail expression was investigated by immunohistochemistry in an OSCC cohort containing 217 tissue samples from patients with long-term follow-up. The influence of the Axin2-Snail axis on the biological behaviour of OSCC cells and CAFs was further investigated both in vitro and in vivo.

Results: Axin2 expression was significantly associated with Snail expression, the desmoplasia status, and bone invasion in patients with OSCC. In multivariate analysis, lymph node metastasis, desmoplasia, Axin2 expression, and Snail expression were independent poor prognostic factors in our cohort. Consistent with these findings, OSCC cells demonstrated attenuated oncogenic activity as well as decreased expression of Snail and various cytokines after Axin2 knockdown in vitro. Among the related cytokines, C-C motif chemokine ligand 5 (CCL5) and interleukin 8 (IL8) demonstrated a strong influence on the biological behaviour of CAFs in vitro. Moreover, both the desmoplastic reaction and osteolytic lesions in the calvaria were predominantly decreased after Axin2 knockdown in OSCC cells in vivo using a BALB/C athymic nude mouse xenograft model.

Conclusions: Oncogenic activities of the Axin2-Snail axis are not limited to the cancer cells themselves but rather extend to CAFs via regulation of the cytokine-mediated cancer-stromal interaction, with further implications for bone invasion as well as a poor prognosis in OSCC.
\end{abstract}

Keywords: Axin2, Snail, Cytokine, Cancer-stroma crosstalk, CAFs, Bone invasion, Prognosis, OSCC

\section{Background}

Oral squamous cell carcinoma (OSCC) is the most common histological type of oral cancer. OSCC cells often penetrate underlying bone, and $12-56 \%$ of patients with

\footnotetext{
* Correspondence: lingjq@mail.sysu.edu.cn; zhangxianglan@yuhs.ac

${ }^{\dagger}$ Yin-Zhe An and Eunae Cho contributed equally to this work.

'Key laboratory of Oral Medicine, Guangzhou Institute of Oral Disease,

Affiliated Stomatology Hospital of Guangzhou Medical University, Guangzhou, Guangdong, China

${ }^{4}$ Oral Cancer Research Institute, Yonsei University College of Dentistry, Seoul, Republic of Korea

Full list of author information is available at the end of the article
}

OSCC present with bone invasion [1]. According to the American Joint Committee on Cancer (AJCC) classification, the presence of bone invasion can upstage this type of cancer regardless of tumour size because bone invasion is a major poor prognostic indicator of OSCC [2-4]. However, the molecular mechanism underlying the invasion of adjacent bone by OSCC is not fully understood.

Desmoplasia refers to the growth of excessive stromal tissue around tumours, and fibroblasts located in this stromal tissue, termed cancer-associated fibroblasts (CAFs), are key players in the cancer stroma. The critical

(c) The Author(s). 2020 Open Access This article is licensed under a Creative Commons Attribution 4.0 International License, which permits use, sharing, adaptation, distribution and reproduction in any medium or format, as long as you give appropriate credit to the original author(s) and the source, provide a link to the Creative Commons licence, and indicate if changes were made. The images or other third party material in this article are included in the article's Creative Commons licence, unless indicated otherwise in a credit line to the material. If material is not included in the article's Creative Commons licence and your intended use is not permitted by statutory regulation or exceeds the permitted use, you will need to obtain permission directly from the copyright holder. To view a copy of this licence, visit http://creativecommons.org/licenses/by/4.0/. The Creative Commons Public Domain Dedication waiver (http://creativecommons.org/publicdomain/zero/1.0/) applies to the data made available in this article, unless otherwise stated in a credit line to the data. 
roles of CAFs have been investigated recently in various types of cancer [5-8]. CAFs promote angiogenesis via the production of pro-angiogenic factors such as fibroblast growth factor 2 (FGF2) and vascular endothelial growth factor A (VEGFA) and contribute to immune surveillance in tumour cells by recruiting immunosuppressive cells such as myeloid-derived suppressor cells (MDSCs) and M2 macrophages [9-11]. Moreover, CAFderived hepatocyte growth factor (HGF), stromal cellderived factor 1 (SDF1), and transforming growth factor beta (TGF- $\beta$ ) promote the proliferation, invasion, and metastasis of cancer cells by activating various signalling pathways, such as the MAPK and PI3K/AKT pathways, as well as the TGF- $\beta /$ SMAD pathway [12-14]. In boneinvasive OSCC, an abundant population of stromal cells intervenes between OSCC cells and damaged bony tissue. In particular, alpha-smooth muscle actin ( $\alpha$-SMA)positive CAFs, a major component of the cancer-related stroma, have been shown to infiltrate into bony tissue ahead of OSCC cells [15]. The biological characteristics of CAFs may be important in the pathogenesis of bone invasion in OSCC.

CAFs demonstrate heterogeneity in tumour tissues. In pancreatic adenocarcinomas, for example, CAFs display two distinct populations, myofibroblasts and inflammatory fibroblasts, while in breast cancer, four different populations of CAFs are observed, including those related to immune escape $[16,17]$. Moreover, studies on various cancers, including OSCC, have revealed the presence of a senescence-associated secretory phenotype of CAFs that can secrete various cytokines and thereby influence the tumour microenvironment [18-20]. The stromal role may differ according to the particular population of CAFs.

The production as well as transdifferentiation of CAFs may be regulated by cancer-stromal crosstalk. Some tumour-derived factors, particularly proinflammatory cytokines, trigger cancer-stromal crosstalk and further influence multifaceted signalling pathways responsible for cancer progression, thereby promoting the formation of a favourable microenvironment for tumour cell survival, growth, and invasion [21, 22]. Recently, therefore, CAFs have become regarded as a potential target to increase the therapeutic efficacy of the treatment of various cancers with desmoplastic features [23]. Accordingly, targeting the key genetic factors involved in the desmoplastic reaction in cancers may enable therapeutic advances for patients resistant to current anti-cancer therapy.

Epithelial to mesenchymal transition (EMT) is mediated by local activation of the canonical Wnt signalling pathway in various types of cancer and promotes cell invasion and metastasis during cancer progression by silencing epithelial traits and inducing mesenchymal phenotypes [24]. On the invasive front, cancer cells are exposed to the extracellular matrix and can thereby participate in cancer-stromal crosstalk. Snail, a zinc-finger transcription factor, is primarily known as a transcriptional repressor that mediates EMT via the repression of E-cadherin transcription [25-27]. Recently, increasing evidence has demonstrated that Snail-mediated transactivation can remodel the tumour microenvironment during EMT progression. The transcription of multiple proinflammatory cytokines, such as $\mathrm{C}-\mathrm{C}$ motif chemokine ligand (CCL) 2 and CCL5, is activated by Snail transactivation [28, 29]. Moreover, Snail can also directly activate interleukin (IL) 8 transcription by binding to the E3/E4 E-boxes [30]. In addition, Snail activates TGF- $\beta$ signalling pathway-related proteins, such as connective tissue growth factor, secreted protein acidic and rich in cysteine, fibronectin 1 , and transgelin, which are involved in fibrosis in various organs. Axis inhibition protein 2 (Axin2), a scaffolding protein of glycogen synthase kinase 3 (GSK-3), promotes cancer cell invasion and metastasis in various types of malignancies by inhibiting GSK-3mediated Snail degradation [25, 31]. Axin2-mediated Snail stabilization may contribute to cancer-stromal crosstalk and thereby may influence cancer prognosis.

In the present study, the association between Axin2 expression and various clinicopathological factors, including the desmoplasia status as well as bone invasion, was investigated in patients with OSCC. The influence of Axin2 expression on the biological behaviour of CAFs was also investigated in vitro and in vivo with the aim of identifying the possible role of Axin2 expression in the pathogenesis of OSCC.

\section{Methods}

\section{Patients in the OSCC cohort}

In this study, we retrospectively reviewed the archived files of patients with OSCC at Dental Hospital, Yonsei University Medical Center, Seoul, Korea, from 1999 to 2017. Of the 432 patients reviewed, 217 with OSCC occurring in lesion sites that might involve the maxilla and/ or the mandible were included in the present study. Of these 217 patients in the OSCC cohort, 123 (56.7\%) had been determined during follow-up to have bone invasion, while no bone invasion had been found in the other 94 (43.3\%) patients (Fig. 1). The clinicopathological characteristics of the patients in the OSCC cohort are shown in Table 1 . This study was approved by the Institutional Review Board for Bioethics of the Yonsei University College of Dentistry (IRB 2-2017-0006 and 2-2019-0050).

\section{Immunochemical staining}

The protein expression of $\alpha$-SMA, vimentin, CD31, Axin2, and Snail in cells and tissue samples was determined by immunochemical staining. Details on the procedures and scoring methods of immunochemical 


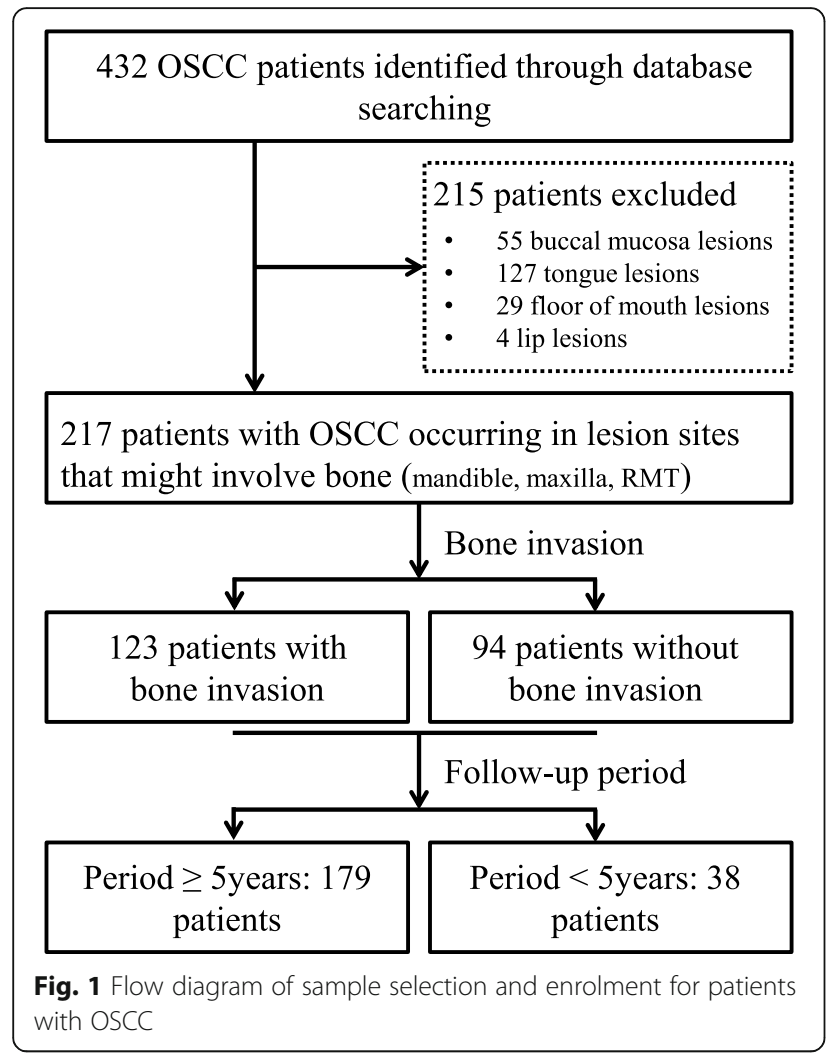

staining are described in the Supplementary Materials and Methods.

\section{Histomorphometry}

As described in a previous study, the desmoplastic reaction status was evaluated according to the ratio of the area of the tumour-associated stroma to that of the whole tumour tissue [32]. Histologic images were obtained using the light microscope (Olympus $\mathrm{BX} 53^{\circ}$, Tokyo, Japan) with an attached digital camera (DP27 ${ }^{\circ}$, Japan) and Olympus cellSens ${ }^{\mathrm{Th}}$ Entry software. The subjected areas were measured on haematoxylin and eosin-stained OSCC tumour tissue sections with ImageJ software. The desmoplasia status was further divided into two groups according to the calculated ratio: high $($ ratio $\geq 1)$ and low desmoplastic $($ ratio $<1)$ reaction.

\section{Cell lines}

Two kinds of CAFs (CAF1 and CAF2) and two OSCC cell lines (CA9-22 and HSC-2) were used in this study. Details on the procedures of cell culture and the establishment of Axin2-knockdown OSCC cells are described in the Supplementary Materials and Methods.

\section{Recombinant proteins}

All of the human recombinant proteins (CCL2, CCL5, and IL8) were purchased from R\&D Systems (Minneapolis, MN, USA).
Table 1 Clinicopathological characteristics of 217 OSCC patients

\begin{tabular}{|c|c|}
\hline Clinicopathological variables & No. of patients (\%) \\
\hline Total cases & 217 \\
\hline \multicolumn{2}{|l|}{ Age, years } \\
\hline Median age (range) & $61(27-85)$ \\
\hline$\leq 61$ & $113(52.1)$ \\
\hline$>61$ & $104(47.9)$ \\
\hline \multicolumn{2}{|l|}{ Sex } \\
\hline Male & $141(65.0)$ \\
\hline Female & $76(35.0)$ \\
\hline \multicolumn{2}{|l|}{ Site } \\
\hline Mandible & $112(51.6)$ \\
\hline Maxilla & $67(30.9)$ \\
\hline RMT & $38(17.5)$ \\
\hline \multicolumn{2}{|l|}{ T stage } \\
\hline $\mathrm{T} 1$ & $27(12.4)$ \\
\hline $\mathrm{T} 2$ & $45(20.7)$ \\
\hline T3 & $9(4.1)$ \\
\hline T4 & $136(62.7)$ \\
\hline \multicolumn{2}{|l|}{ N stage } \\
\hline $\mathrm{Nx}$ & $48(22.1)$ \\
\hline No & $95(43.8)$ \\
\hline $\mathrm{N} 1$ & $23(10.6)$ \\
\hline $\mathrm{N} 2 \mathrm{a}$ & $9(4.1)$ \\
\hline $\mathrm{N} 2 \mathrm{~b}$ & $25(11.5)$ \\
\hline $\mathrm{N} 2 \mathrm{C}$ & $1(0.5)$ \\
\hline N3b & $16(7.4)$ \\
\hline \multicolumn{2}{|l|}{ Histologic grade } \\
\hline WD & $35(16.1)$ \\
\hline MD & $149(68.7)$ \\
\hline PD & $33(15.2)$ \\
\hline \multicolumn{2}{|l|}{ Perineural invasion } \\
\hline Negative & $202(93.1)$ \\
\hline Postive & $15(6.9)$ \\
\hline \multicolumn{2}{|l|}{ Vascular invasion } \\
\hline Negative & $192(88.5)$ \\
\hline Postive & $25(11.5)$ \\
\hline \multicolumn{2}{|l|}{ Bone invasion } \\
\hline Negative & $94(43.3)$ \\
\hline Postive & $123(56.7)$ \\
\hline
\end{tabular}

WD well differenciated, $M D$ moderately differentiated, $P D$ poorly differentiated

\section{Proliferation assay}

To investigate the proliferative ability of each group of cells, OSCC cells $\left(1 \times 10^{5} /\right.$ well $)$ and CAFs $\left(5 \times 10^{4} /\right.$ well $)$ were seeded into 6-well plates at approximately $30 \%$ confluency. The number of cells was counted after trypan blue staining at each indicated time point. 


\section{Wound healing and invasion assays}

Cell motility and invasion ability were determined for each group of cells using wound healing and Matrigel invasion assays, respectively. Details on the procedures of wound healing and invasion assays are described in the Supplementary Materials and Methods.

\section{Quantitative reverse transcription polymerase chain reaction (RT-PCR)}

Quantitative RT-PCR was performed to determine the mRNA expression of IL8, CCL2, CCL5, matrix metalloproteinase (MMP)-2, MMP-9, and Ki67 in the cell lines. Details on the RT-PCR procedure are described in the Supplementary Materials and Methods.

\section{Nude mouse xenograft model}

The animal studies were performed according to experimental protocols approved by the Animal Ethics Committee of the Yonsei University College of Dentistry. Twenty female 5-week-old BALB/c athymic nude mice (Central Laboratory Animal Inc., Seoul, Korea) were housed in laminar flow cabinets under specific pathogen-free conditions.

CAFs are derived from resident fibroblasts, bone marrow-derived mesenchymal precursor cells, adipocytes, endothelial cells, and EMT, endothelial to mesenchymal transition (EndMT), and various cytokines are implicated in the production of CAFs [33]. As wellknown EMT genes, those involved in the Axin2-Snail axis may also contribute to the production of CAFs. In this study, we aimed to investigate the influence of Axin2 knockdown on both the production and biological behaviour of CAFs using a xenograft mouse model.

All of the mice were randomized into four groups ( $n=5$ per group), and a total of $1 \times 10^{6} \mathrm{HSC}^{\text {Mock }}$, HSC-2 $2^{\triangle \text { Axin2 }}$, CA9-22 $2^{\text {Mock }}$, and CA9-22 $2^{\triangle \text { Axin2 }}$ cells were subcutaneously injected into the calvaria of the mice. The length and width of the tumour nodules were measured every 3 days, and the size of the tumours was calculated with the following formula: width ${ }^{2} \times$ length $\times 1 / 2$. We have acquired micro-computed tomography (microCT) images with Skyscan 1173 (Bruker-microCT, Kontich, Beigium) and reconstructed those images with Nrecon software. All of the mice were sacrificed after 9 weeks by $\mathrm{CO}_{2}$ asphyxiation.

\section{Statistical analysis}

The association between protein expression and clinicopathological variables was analysed using the chi-square test. The Mann-Whitney U-test was used to compare proliferation, migration, invasion, and tumorigenesis between groups. SPSS software version 23.0 (SPSS Inc., Chicago, IL, USA) was used for statistical analysis, and a $p$-value less than 0.05 was considered statistically significant.

\section{Results}

Clinicopathological significance of Axin2 and snail expression in patients with OSCC

In the present study, Axin2 expression was found in the cytoplasm of cancer cells in 168 (77.4\%) patients with OSCC, and immunoreactivity against Axin2 was high in 101 (high-Axin2, 46.5\%) OSCC tissue samples and low in 116 (low-Axin2, 53.5\%). Cancer cells demonstrated cytoplasmic and nuclear Snail expression in 186 (85.7\%) patients with OSCC, and immunoreactivity against Snail was high in 107 (high Snail, 49.3\%) OSCC tissue samples and low in 110 (low Snail, 50.7\%). A significant association was found between Axin2 expression and Snail expression in patients with OSCC $(p=0.006)$ (Fig. 2a). Both high Axin2 expression and high Snail expression showed a significant association with $\mathrm{T}$ stage $(p<0.001$ and $p=0.031$ ), lymph node metastasis (both $p<0.001$ ), vascular invasion $(p=0.01$ and $p=0.019)$, and bone invasion $(p<0.001$ and $p=0.028)$ in the present study. The sex differences in the prognosis of OSCC patients remain controversial [34]. In our study, we did not find a significant association between sex and the prognosis of OSCC. Moreover, there was no significant association between sex and Axin2 or Snail expression in our cohort. The current edition of the "Classification of Head and Neck Tumors" suggests three histological grades for conventional OSCC: well-, moderately, and poorly differentiated variant, in spite the fact that they remark grading as 'Grading alone does not correlate well with prognosis' [35]. Consistent with this, we did not find a significant association between histological grade and prognosis in our cohort. High Axin2 expression showed a tendency to gradually increase from well-differentiated OSCC $(37.1 \%, 13 / 35)$ to moderately differentiated OSCC $(47.7 \%, 71 / 149)$ to poorly differentiated OSCC $(51.5 \%$, 17/33). However, there were no significant differences between the groups (Table 2).

Moreover, patients with high Axin2 or high Snail expression demonstrated increased vessel density $(p<$ 0.001 and $p=0.002$ ) and a higher desmoplastic reaction (both $p<0.001$ ) than patients with low Axin2 or low Snail expression in our cohort (Fig. 2b and c). To identify the risk factors for the prognosis of OSCC, multivariate analysis was performed in 179 patients who were followed up for more than 5 years. The results showed that when using age, sex, lesion site, $\mathrm{T}$ stage, lymph node metastasis, histologic grade, vascular invasion, perineural invasion, bone invasion, desmoplasia status, angiogenesis status, Axin2 expression, and Snail expression as cofactors, lymph node metastasis, desmoplasia status, Axin2 expression, and Snail expression were independent risk factors for OSCC prognosis, with hazard ratios of 3.424 (95\% confidence interval, 1.466-7.998; $p=0.004$ ), 2.491 (95\% confidence interval, 1.240-5.004; 


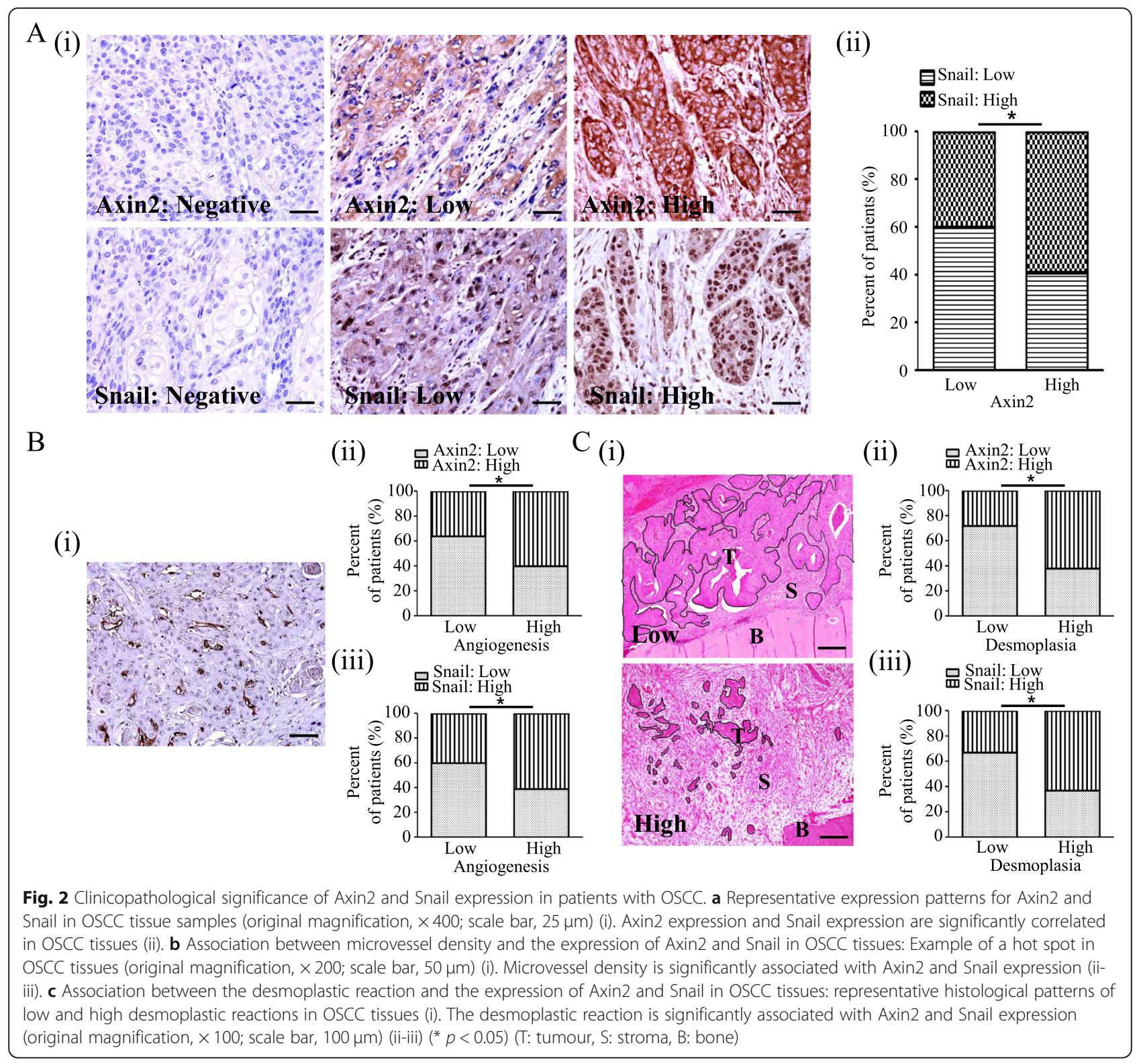

$p=0.01), 2.488$ (95\% confidence interval, 1.358-4.559; $p=0.003$ ), and 1.984 (95\% confidence interval, $1.097-$ $3.588 ; p=0.024$ ), respectively (Table 3 ).

\section{Axin2 knockdown had a strong influence on the biological behaviour of OSCC cells}

Consistent with the results of a previous study [25], we found that Snail expression was predominantly decreased in both CA9-2 $2^{\triangle \mathrm{Axin} 2}$ and $\mathrm{HSC}-2^{\triangle \mathrm{Axin} 2}$ cells compared to the related control cells (Supplementary Fig. A, i and iv).

Proliferative ability was significantly reduced after Axin2 knockdown in both CA9-22 and HSC-2 cells. Compared with CA9-22 ${ }^{\text {Mock }}$ cells, decreases of 1.4-, 2.1-, and 2.2-fold in cell number were found in CA9-22 ${ }^{\triangle \mathrm{Axin} 2}$ cells after $24 \mathrm{~h}$, $48 \mathrm{~h}$, and $72 \mathrm{~h}$ of culture (all $p=0.008$ ). Similarly, HSC- $2^{\triangle \mathrm{Axin} 2}$ cells also showed decreases of 1.4-, 1.6-, and 2.3-fold in number compared to HSC-2 $2^{\text {Mock }}$ cells (all $p=0.008$ ) (Supplementary Fig. A, ii and v). Likewise, Ki67 expression was significantly decreased in Axin2-knockdown cells compared to both HSC-2 and CA9-22 control cells (both $p=$ 0.002) (Supplementary Fig. A, iii and vi). In addition, cell motility was decreased 1.5- and 1.8-fold, respectively, in Axin2-knockdown cells compared to CA9-22 and HSC-2 control cells (both $p=0.002$ ) (Supplementary Fig. B, i-iv). Moreover, 2.3- and 1.6-fold decreases in the numbers of invading cells were found in Axin2-knockdown cells compared to CA9-22 and HSC-2 control cells, respectively (both $p=0.002$ ). Axin2 may have oncogenic activity in OSCC cells (Supplementary Fig. C, i-iv). Interestingly, compared to the related control cells, the expression of Snail- 
Table 2 Clinicopathological significance of Axin2 and Snail expression in 217 OSCC patients

\begin{tabular}{|c|c|c|c|c|c|c|c|}
\hline \multirow[t]{2}{*}{ Variables } & \multirow[t]{2}{*}{ Total } & \multicolumn{2}{|l|}{ Axin2 } & \multirow[t]{2}{*}{$P$} & \multicolumn{2}{|l|}{ Snail } & \multirow[t]{2}{*}{$P$} \\
\hline & & Low & High & & Low & High & \\
\hline \multicolumn{8}{|l|}{ Age } \\
\hline$\leq 61$ & 113 & $65(57.5)$ & $48(42.5)$ & \multirow[t]{2}{*}{0.211} & $60(53.1)$ & $53(46.9)$ & \multirow[t]{2}{*}{0.46} \\
\hline$>61$ & 104 & $51(49.0)$ & $53(51.0)$ & & $50(48.1)$ & $54(51.9)$ & \\
\hline \multicolumn{8}{|l|}{ Sex } \\
\hline Male & 141 & $69(48.9)$ & $72(51.1)$ & \multirow[t]{2}{*}{0.069} & $74(52.5)$ & $67(47.5)$ & \multirow[t]{2}{*}{0.472} \\
\hline Female & 76 & $47(61.8)$ & $29(38.2)$ & & $36(47.4)$ & $40(52.6)$ & \\
\hline \multicolumn{8}{|l|}{ Site } \\
\hline Mandible & 112 & $66(58.9)$ & $46(41.1)$ & \multirow[t]{3}{*}{0.173} & $60(53.6)$ & $52(46.4)$ & \multirow[t]{3}{*}{0.681} \\
\hline Maxilla & 67 & $34(50.7)$ & $33(49.3)$ & & $32(47.8)$ & $35(52.2)$ & \\
\hline RMT & 38 & $16(42.1)$ & $22(57.9)$ & & $18(47.4)$ & $20(52.6)$ & \\
\hline \multicolumn{8}{|l|}{ T stage } \\
\hline $\mathrm{T} 1-\mathrm{T} 2$ & 72 & $51(70.8)$ & $21(29.2)$ & \multirow[t]{2}{*}{$<0.001$} & $44(61.1)$ & 28 (38.9) & \multirow[t]{2}{*}{0.031} \\
\hline T3-T4 & 145 & $65(44.8)$ & $80(55.2)$ & & $66(45.5)$ & 79 (54.5) & \\
\hline \multicolumn{8}{|l|}{ N stage } \\
\hline $\mathrm{Nx}$ & 48 & 31 (64.6) & 17 (35.4) & \multirow[t]{3}{*}{$<0.001$} & $29(60.4)$ & 19 (39.6) & \multirow[t]{3}{*}{$<0.001$} \\
\hline NO & 95 & $62(65.3)$ & $33(34.7)$ & & $57(60.0)$ & $38(40.0)$ & \\
\hline$N 1-3$ & 74 & $23(31.1)$ & $51(68.9)$ & & $24(32.4)$ & $50(67.6)$ & \\
\hline \multicolumn{8}{|c|}{ Histologic grade } \\
\hline WD & 35 & $22(62.9)$ & $13(37.1)$ & \multirow[t]{3}{*}{0.439} & $19(54.3)$ & $16(45.7)$ & \multirow[t]{3}{*}{0.565} \\
\hline$M D$ & 149 & $78(52.3)$ & $71(47.7)$ & & $77(51.7)$ & $72(48.3)$ & \\
\hline PD & 33 & $16(48.5)$ & $17(51.5)$ & & $14(42.4)$ & 19 (57.6) & \\
\hline \multicolumn{8}{|c|}{ Perineural invasion } \\
\hline Negative & 202 & $110(54.5)$ & $92(45.5)$ & \multirow[t]{2}{*}{0.279} & $105(52.0)$ & $97(48.0)$ & \multirow[t]{2}{*}{0.163} \\
\hline Postive & 15 & $6(40.0)$ & $9(60.0)$ & & $5(33.3)$ & $10(66.7)$ & \\
\hline \multicolumn{8}{|c|}{ Vascular invasion } \\
\hline Negative & 192 & $109(56.8)$ & $83(43.2)$ & \multirow[t]{2}{*}{0.01} & $103(53.6)$ & $89(46.4)$ & 0.019 \\
\hline Postive & 25 & $7(28.0)$ & $18(72.0)$ & & $7(28.0)$ & $18(72.0)$ & \\
\hline Bone invasio & & & & & & & \\
\hline Negative & 94 & $63(67.0)$ & $31(33.0)$ & $<0.001$ & $56(59.6)$ & $38(40.4)$ & 0.028 \\
\hline Postive & 123 & $53(43.1)$ & $70(56.9)$ & & $54(43.9)$ & $69(56.1)$ & \\
\hline
\end{tabular}

WD well differenciated, $M D$ moderately differentiated, $P D$ poorly differentiated

related cytokines IL8, CCL2, and CCL5 was 3.5-fold, 2.8fold, and 3.3-fold decreased, respectively, in CA9-2 $2^{\triangle \mathrm{Axin} 2}$ cells (all $p=0.002$ ) and 2.6-fold, 1.8-fold, and 1.5-fold decreased, respectively, in $\mathrm{HSC}-2^{\triangle \mathrm{Axin} 2}$ cells (all $p=0.002$ ) (Supplementary Fig. D, i-ii).

\section{Cytokines related to the Axin2-snail axis exert strong influences on the biological behaviour of CAFs}

To evaluate the effect of these cytokines on the biological behaviour of CAFs, both CAF1 and CAF2 cells were treated with different doses $(0,2,5$, and $10 \mathrm{ng} / \mathrm{ml})$ of human recombinant proteins (IL8, CCL2, and CCL5), after which the proliferation and invasion abilities of CAFs in each group were comparatively investigated. A strong influence of IL8 or CCL5 on the biological behaviour of CAFs was found at a dose of $2 \mathrm{ng} / \mathrm{ml}$ in the present study. CAF1 cells showed increases of 2.5- and 2.0-fold in the numbers of cells after treatment with $2 \mathrm{ng} / \mathrm{ml}$ IL8 or CCL5, respectively, compared to untreated control cells (both $p=0.002$ ). Similar results were obtained using CAF2, with IL8 or CCL5 treatment leading to increases in cell numbers (both $p=0.002$ ). No significant differences were observed in the proliferative ability of CAFs after CCL2 treatment in this study (Fig. 3b, i-ii).

We also found that the invasion ability of CAF1 and CAF2 cells was 2.2- and 2.3-fold increased, respectively, after IL8 $(2 \mathrm{ng} / \mathrm{ml})$ treatment compared to untreated 
Table 3 Prognostic impact of clinical variables and biomarkers in multivariate Cox regression analysis in 179 OSCC patients

\begin{tabular}{|c|c|}
\hline & Hazard ratio $(95 \% \mathrm{Cl})$ \\
\hline Age & $0.825(0.482-1.410)$ \\
\hline Sex & 0.609 (0.339-1.093) \\
\hline \multicolumn{2}{|l|}{ Lesion site } \\
\hline Mandible & 1 \\
\hline Maxilla & $0.618(0.289-1.323)$ \\
\hline RMT & $1.206(0.608-2.392)$ \\
\hline \multicolumn{2}{|l|}{ T stage } \\
\hline $\mathrm{T} 1$ & \\
\hline $\mathrm{T} 2$ & 0.989 (0.319-3.066) \\
\hline T3 & 1.059 (0.119-9.453) \\
\hline T4 & $1.157(0.386-3.467)$ \\
\hline \multicolumn{2}{|l|}{ N stage } \\
\hline \multicolumn{2}{|l|}{$\mathrm{Nx}$} \\
\hline NO & $1.927(1.016-3.655)$ \\
\hline$N 1-3$ & $3.424(1.466-7.998)$ \\
\hline \multicolumn{2}{|l|}{ Histologic grade } \\
\hline WD & 1 \\
\hline MD & $1.209(0.592-2.467)$ \\
\hline PD & $1.665(0.730-3.798)$ \\
\hline Perineural invasion & $0.850(0.321-2.247)$ \\
\hline Vascular invasion & $1.036(0.457-2.350)$ \\
\hline Bone invasion & $1.357(0.572-3.219)$ \\
\hline Desmoplasia & $2.491(1.240-5.004)$ \\
\hline Angiogenesis & $1.449(0.860-2.441)$ \\
\hline Axin2 & $2.488(1.358-4.559)$ \\
\hline Snail & $1.984(1.097-3.588)$ \\
\hline
\end{tabular}

$W D$ well differenciated, $M D$ moderately differentiated, $P D$ poorly differentiated, 95\% Cl 95\% confidence interval

control cells (both $p=0.002$ ). Consistent with these findings, MMP-2 expression was 2.3-fold and 2.2-fold increased after IL8 $(2 \mathrm{ng} / \mathrm{ml})$ treatment in both CAF1 and CAF2 cells, respectively, compared to untreated control cells (both $p=0.002$ ). No significant difference was found in MMP-9 expression in CAFs after IL8 treatment in our study (Fig. 3c, i-vi).

Tumour progression and bone invasion depend on Axin2 expression in tumour cells in vivo

As shown in Fig. 4, tumour volume was significantly decreased in mice injected with Axin2-knockdown cells compared to both CA9-22 and HSC-2 control cells (A, i-ii). In micro-CT imaging analysis, extensive osteolytic lesions were observed in the calvaria from CA9-22 $2^{\text {Mock }}$ or $\mathrm{HSC}-2^{\text {Mock }}$ cell-bearing mice compared to the related Axin2-knockdown cell-bearing mice (B, i-ii). Moreover, in the tissue sections, the area of the tumour-associated stroma was predominantly increased at the tumour-bone interface in CA9-22 $2^{\text {Mock }}$ or HSC-2 ${ }^{\text {Mock }}$ cell-bearing mice compared to the related Axin2-knockdown cell-bearing mice $(\mathrm{C}, \mathrm{i}-\mathrm{ii})$.

\section{Discussion}

Although earlier studies focused on the inhibitory role of Axin2 in the $\beta$-catenin degradation complex, recent studies have implied that Axin2 contributes to oncogenic progression. Increased expression of Axin2 was found after the loss of adenomatous polyposis coli (APC), a key tumour suppressor gene, in colorectal cancer, and the knockdown of Axin2 attenuated oncogenic and Wnt signalling activities in cancer cells $[36,37]$. The GSK3 nuclear export function of the Axin2-mediated abundance of nuclear Snail and $\beta$-catenin is also a sign of the oncogenic activity of Axin2 [25]. In our previous study, we found that Axin2 expression showed a positive correlation with Snail expression, and increased expression of both Axin2 and Snail was closely associated with the malignant transformation of oral leukoplakia [38]. Consistent with these findings, high Axin2 expression and high Snail expression are significantly correlated in OSCC tissues. Moreover, we found that both Axin2 expression and Snail expression were significantly related to a poor prognosis and serve as poor prognostic indicators of OSCC, including bone invasion in OSCC. Consistent with these results, Axin2-knockdown cells showed decreased Snail expression and attenuated oncogenic activities compared to control cells. Axin 2 may be implicated in OSCC pathogenesis as an oncogene.

Desmoplasia is a typical sign of aggressiveness in various types of cancer, including OSCC [15, 39]. Some investigators have shown that an abundant desmoplastic reaction is prominent in the cancer-bone interface of OSCC with bone invasion, but an identifiable fibrous stroma has been less frequently found in ameloblastoma, a benign odontogenic epithelial tumour with features of bone invasion [15]. In the present study, we also found frequent desmoplastic reactions in OSCC tissues, especially in the area of bone invasion, and the desmoplasia status was significantly associated with bone invasion in patients with OSCC. Interestingly, both Axin2 expression and Snail expression were positively correlated with the desmoplastic reaction in our cohort. Moreover, in the mouse xenograft analysis, the stromal component of tumour nodules as well as the osteolytic bone resorption of mouse calvaria were predominantly decreased in the group of cells with Axin2 knockdown compared to control cells. In addition, the expression of Snail-mediated proinflammatory cytokines, such as IL8, CCL2, and CCL5, was significantly decreased after Axin2 knockdown in OSCC cells compared to control cells. Admittedly, all of these cytokines are related to characteristics 


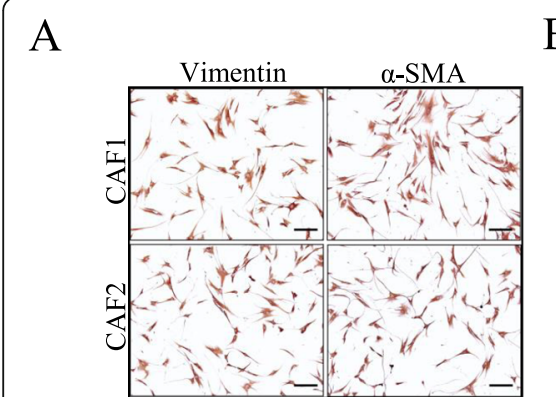

$\mathrm{C}_{(\mathrm{i})}$

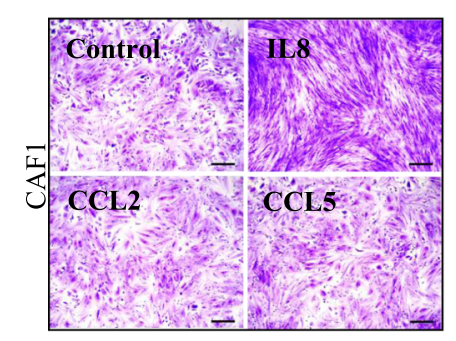

(iv)

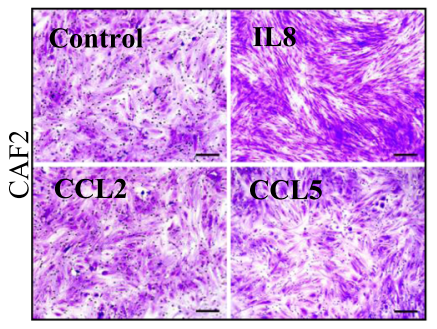

B

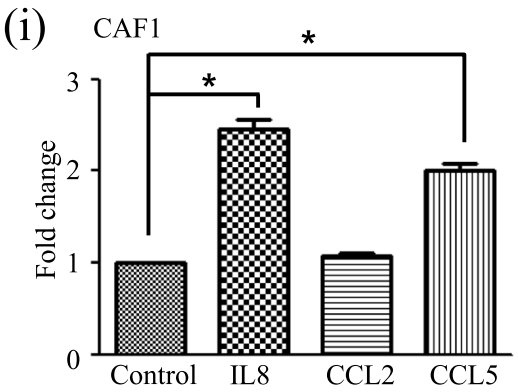

(ii)

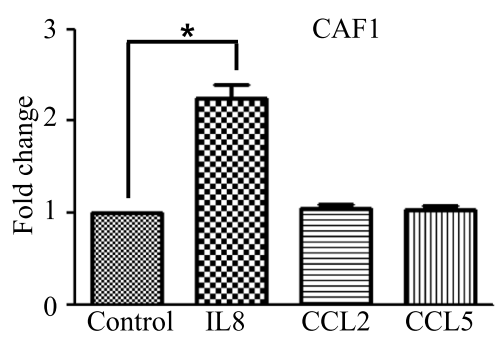

(v)

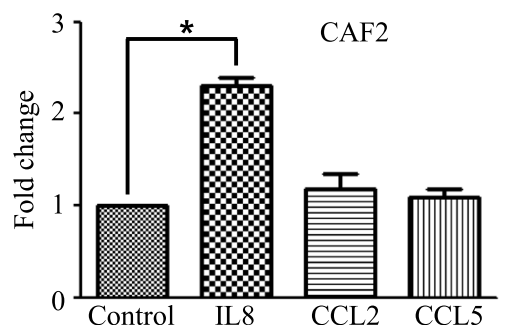

(ii)

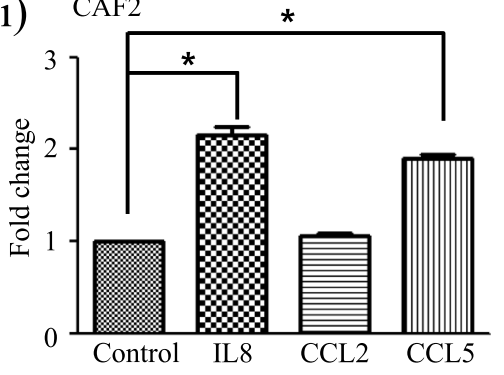

(iii)

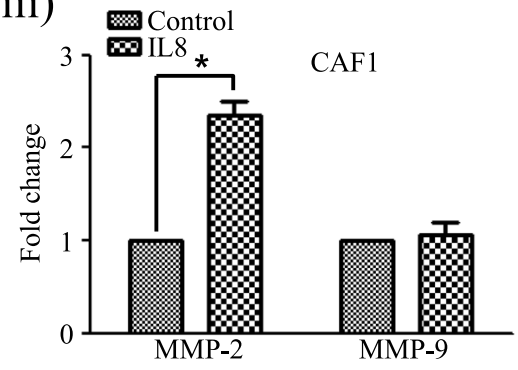

(vi)

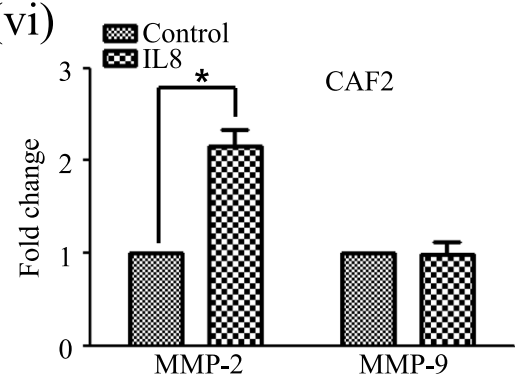

Fig. 3 Cytokines related to the Axin2-Snail axis exert strong influences on the biological behaviour of cancer-associated fibroblasts (CAFs) in vitro. a CAF identities were verified based on the expression of vimentin and a-SMA. b Proliferation was significantly increased after CCL5 or IL8 treatment in both CAF1 and CAF2 cells (i \& ii). c Invasion ability and MMP-2 expression were significantly increased after IL8 treatment in both CAF1 (i-iii) and CAF2 (iv-vi) cells (original magnification, $\times 100$; scale bar, $100 \mu \mathrm{m})\left(^{*} p<0.05\right)$

of aggressiveness by means of promoting the migration, invasion, and metastatic abilities of cancer cells, including those of OSCC, and are considered potential therapeutic targets of malignancies [40-44].

According to previous studies, all of these tumourderived cytokines also influence different types of cells in the stromal component of tumours, such as CAFs, endothelial cells, and inflammatory cells, and thereby trigger multiple signalling pathways related to the malignant progression of tumours. Both CCL2 and CCL5 mediate the infiltration of tumour-associated macrophages and inhibit potential anti-tumour T-cell activities, thereby controlling the populations of leukocytes at tumour sites [43]. Moreover, distinct regulatory roles as well as underlying molecular mechanisms performed by CCL2 and IL8 in angiogenesis have been indicated by some investigators. CCL2 enhances angiogenic activity either by directly inducing endothelial cell retraction or by the CCL2-induced release of angiogenic factors such as VEGFA [45, 46]. IL8 promotes the invasion ability of endothelial cells via increased expression of MMP-2 and MMP-9 in endothelial cells [47]. Moreover, IL8 promotes the proliferation and tube formation of endothelial cells by activating extracellular signal-regulated protein kinase $1 / 2$ (Erk1/2) during interaction with CXCR2 in endothelial cells [48]. In the present study, we found that CD31-positive vessel density was significantly associated with Axin2 and Snail expression in patients with OSCC. In OSCC, the Axin2-Snail axis may also mediate angiogenic responses via the control of related cytokines.

A previous study demonstrated that 12 different types of chemokine receptors were found in oral fibroblasts, including CXCR1, CXCR2, and CCR3 [49]. In the 


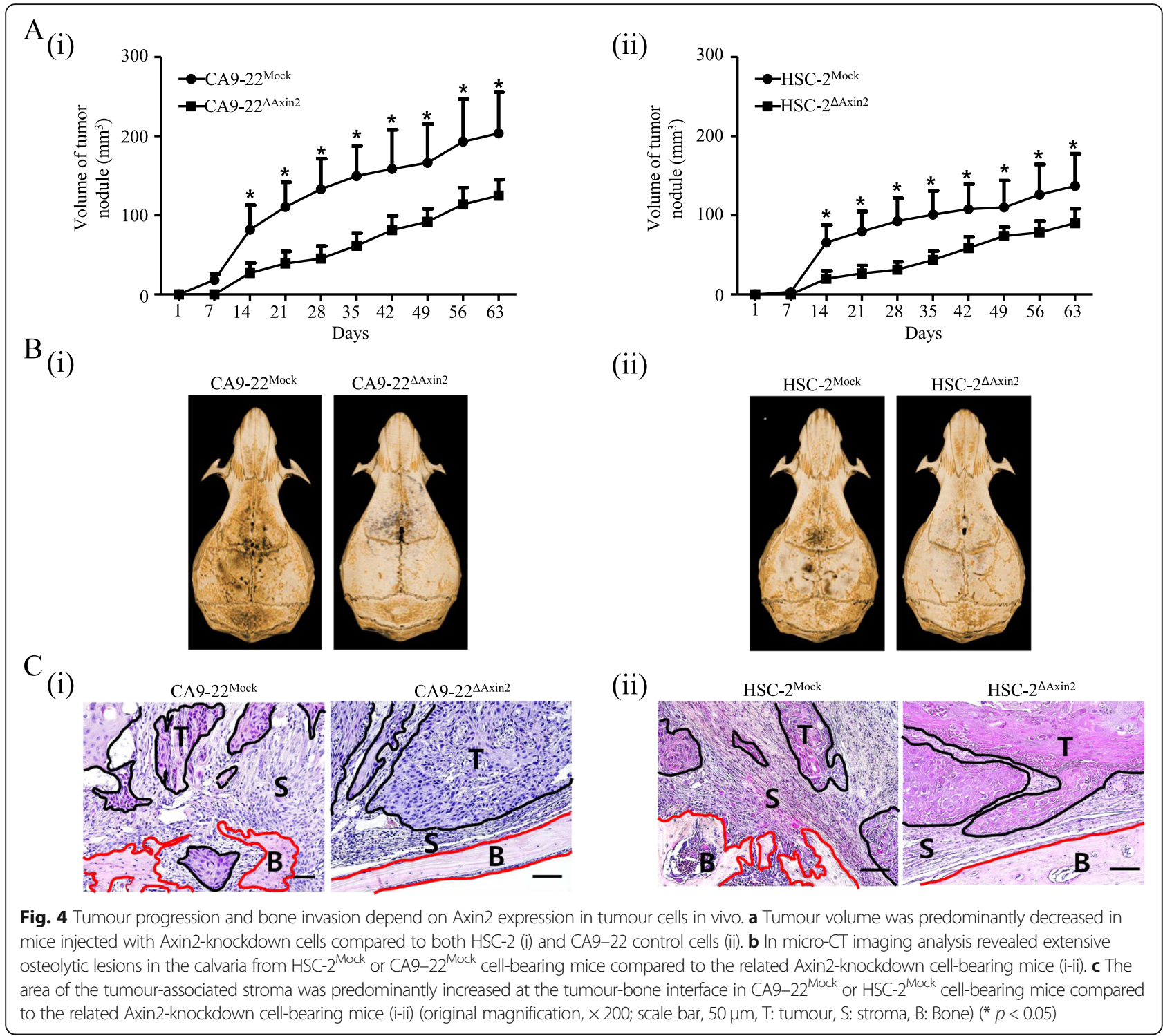

present study, we found that both CCL5 and IL8 have a strong influence on the biological behaviour of CAFs. These cytokines may influence CAFs by binding to related receptors. All of these findings imply that the Axin2-Snail axis mediates a diffuse desmoplastic reaction in OSCC by controlling inflammation-stromal crosstalk.

In the present study, recombinant IL8 increased the invasion ability of CAFs in vitro. In various types of cancer tissues, IL8 participates in degradation of the extracellular matrix by promoting the expression of MMP-2 and MMP-9 in cancer cells [50-53]. According to an analysis of a public data base, MMP-9 acts in a contextdependent manner in different types of cancer [54]. In this study, no significant difference was found in MMP9 expression in CAFs after IL8 treatment. In the present study, we also found that MMP-2 expression was significantly increased in CAFs after IL8 treatment. A previous study showed that MMP-2 was expressed primarily in the fibroblasts of mouse lung tumours and concluded that CAFs were the main producer of MMP-2 [55]. MMPs can directly destroy the bone matrix; thus, IL8mediated MMP-2 overexpression may be one of the underlying molecular mechanisms of CAFs infiltration into bony tissue ahead of OSCC cells in patients with high Axin2 expression.

\section{Conclusions}

Consistent with previous observations in other cancers [25], our results imply that the Axin2-Snail axis is a poor prognostic indicator of OSCC. We also found that the oncogenic activities of the Axin2-Snail axis are not limited to the cancer cells themselves but rather extend to cancer-associated stromal cells such as endothelial cells and CAFs via regulation of the cytokine-mediated 
cancer-stromal interaction, thereby promoting active desmoplastic reactions as well as bone invasion in OSCC. The Axin2-Snail axis may serve as a novel diagnostic and therapeutic target in bone-invasive OSCC.

\section{Supplementary information}

Supplementary information accompanies this paper at https://doi.org/10. 1186/s12885-020-07495-9.

Additional file 1. Supplementary materials and methods

Additional file 2: Figure $\mathbf{S}$. Influence of Axin2 knockdown on the biological behaviour of OSCC cell lines. (A) The expression of both Axin2 and Snail was strongly decreased after Axin2 knockdown in CA9-22 (i) and HSC-2 (iv) cell lines (original magnification, $\times 400$; scale bar, $25 \mu \mathrm{m}$ ). Both the cell number and Ki67 mRNA expression were significantly decreased after Axin2 knockdown in CA9-22 (ii-iii) and HSC-2 cell lines ( $v$ vi). Migration ability was significantly reduced after Axin2 knockdown in both CA9-22 (i-ii) and HSC-2 (iii-iv) cell lines (original magnification, $\times$ 200). (C) Invasion ability was significantly decreased after Axin2 knockdown in both CA9-22 (i-ii) and HSC-2 (iii-iv) cell lines (original magnification, $\times 100$; scale bar, $100 \mu \mathrm{m}$ ). (D) IL8, CCL2, and CCL5 mRNA expression was significantly decreased after Axin2 knockdown in both CA9-22 (i) and HSC-2 (ii) cell lines $(* p<0.05)$

Additional file 3: Supplementary Table 1. The primer sequences for quantitative reverse transcription polymerase chain reaction

\section{Abbreviations}

OSCC: Oral squamous cell carcinoma; CAFs: Cancer-associated fibroblasts; AJCC: American Joint Committee on Cancer; FGF2: Fibroblast growth factor 2; VEGFA: Vascular endothelial growth factor A; MDSC: Myeloid-derived suppressor cell; HGF: Hepatocyte growth factor; SDF1: Stromal cell-derived factor 1; TGF- $\beta$ : Transforming growth factor beta; $a-S M A$ : Alpha-smooth muscle actin; EMT: Epithelial to mesenchymal transition; CCL: C-C motif chemokine ligand; Axin2: Axis inhibition protein 2; GSK-3: Glycogen synthase kinase 3; RT-PCR: Reverse transcription polymerase chain reaction; MMP: Matrix metalloproteinase; EndMT: Endothelial to mesenchymal transition; micro-CT: Micro-computed tomography; APC: Adenomatous polyposis coli; Erk1/2: Extracellular signal-regulated protein kinase 1/2

\section{Acknowledgements}

Not applicable.

\section{Authors' contributions}

$X L Z, E C$, and JQL designed and wrote the manuscript. XLZ and YZA were involved in and performed most of the experiments. XLZ, YZA, and EC participated in data acquisition, data analysis, or data interpretation. All authors have read and approved the manuscript and ensure that this is the case.

\section{Funding}

This work was supported by grants from the National Natural Science Foundation of China (NSFC, No. 81460408), the National Research Foundation of Korea (NRF-2017R1D1A1B03034921, NRF-2017R1C1B1012464, NRF-2020R1I1A1A01073437) and from the BK21 PLUS Project, Yonsei University College of Dentistry, Seoul, Korea. The funding bodies had no role in the study design, data collection and analysis, decision to publish, or preparation of the manuscript.

\section{Availability of data and materials}

The datasets used and/or analysed during the current study are available from the corresponding author on reasonable request.

\section{Ethics approval and consent to participate}

The protocol was approved (IRB 2-2017-0006 and 2-2019-0050) and the informed consent was deemed unnecessary for the retrospective study by the Institutional Review Board for Bioethics (IRB) of the Yonsei University College of Dentistry. For isolation of CAFs, the informed consent was received from the patients and the procedures were approved by the IRB of Yonsei University College of Dentistry (IRB 2-2012-0027).

\section{Consent for publication}

Not applicable.

\section{Competing interests}

The authors declare that they have no competing interests.

\section{Author details}

'Key laboratory of Oral Medicine, Guangzhou Institute of Oral Disease, Affiliated Stomatology Hospital of Guangzhou Medical University, Guangzhou, Guangdong, China. ²Department of Oral Pathology, Yonsei University College of Dentistry, Seoul, Republic of Korea. ${ }^{3}$ BK21 PLUS Project, Yonsei University College of Dentistry, Seoul, South Korea. ${ }^{4}$ Oral Cancer Research Institute, Yonsei University College of Dentistry, Seoul, Republic of Korea. ${ }^{5}$ Department of Endodontics, Guanghua School of Stomatology, Guangdong Provincial Key Laboratory of Stomatology, Sun Yat-Sen University, 56 Lingyuanxi Road, Guangzhou 510055, Guangdong, China. ${ }^{6}$ Department of Pathology, Yanbian University Hospital, Yanji City 133000, Jilin Province, China.

Received: 22 May 2020 Accepted: 5 October 2020

Published online: 12 October 2020

References

1. Chen YL, Kuo SW, Fang KH, Hao SP. Prognostic impact of marginal mandibulectomy in the presence of superficial bone invasion and the nononcologic outcome. Head Neck. 2011;33(5):708-13.

2. Hoffmannova J, Foltan R, VIk M, Sipos M, Horka E, Pavlikova G, Kufa R, Bulik $\mathrm{O}$, Sedy J. Hemimandibulectomy and therapeutic neck dissection with radiotherapy in the treatment of oral squamous cell carcinoma involving mandible: a critical review of treatment protocol in the years 1994-2004. Int J Oral Maxillofac Surg. 2010;39(6):561-7.

3. Lubek J, El-Hakim M, Salama AR, Liu X, Ord RA. Gingival carcinoma: retrospective analysis of 72 patients and indications for elective neck dissection. Br J Oral Maxillofac Surg. 2011;49(3):182-5.

4. Quan J, Johnson NW, Zhou G, Parsons PG, Boyle GM, Gao J. Potential molecular targets for inhibiting bone invasion by oral squamous cell carcinoma: a review of mechanisms. Cancer Metastasis Rev. 2012;31(1-2):209-19.

5. Kumar D, New J, Vishwakarma V, Joshi R, Enders J, Lin F, Dasari S, Gutierrez WR, Leef G, Ponnurangam S, et al. Cancer-associated fibroblasts drive glycolysis in a targetable signaling loop implicated in head and neck squamous cell carcinoma progression. Cancer Res. 2018;78(14):3769-82.

6. Pang T, Yin X, Luo T, Lu Z, Nie M, Yin K, Xue X. Cancer-associated fibroblasts promote malignancy of gastric cancer cells via nodal signalling. Cell Biochem Funct. 2020:38(1):4-11.

7. Galvan JA, Wiprachtiger J, Slotta-Huspenina J, Feith M, Ott K, Kroll D, Seiler CA, Langer R. Immunohistochemical analysis of the expression of cancerassociated fibroblast markers in esophageal cancer with and without neoadjuvant therapy. Virchows Arch. 2020;476(5):725-34.

8. Wu X, Zhou Z, Xu S, Liao C, Chen X, Li B, Peng J, Li D, Yang L. Extracellular vesicle packaged LMP1-activated fibroblasts promote tumor progression via autophagy and stroma-tumor metabolism coupling. Cancer Lett. 2020;478: 93-106.

9. De Palma M, Biziato D, Petrova TV. Microenvironmental regulation of tumour angiogenesis. Nat Rev Cancer. 2017;17(8):457-74.

10. Flavell RA, Sanjabi S, Wrzesinski SH, Licona-Limon P. The polarization of immune cells in the tumour environment by TGFbeta. Nat Rev Immunol. 2010;10(8):554-67.

11. Yang X, Lin Y, Shi Y, Li B, Liu W, Yin W, Dang Y, Chu Y, Fan J, He R. FAP promotes immunosuppression by Cancer-associated fibroblasts in the tumor microenvironment via STAT3-CCL2 signaling. Cancer Res. 2016;76(14):4124-35.

12. Wu X, Chen X, Zhou Q, Li P, Yu B, Li J, Qu Y, Yan J, Yu Y, Yan M, et al. Hepatocyte growth factor activates tumor stromal fibroblasts to promote tumorigenesis in gastric cancer. Cancer Lett. 2013;335(1):128-35.

13. Straussman R, Morikawa T, Shee K, Barzily-Rokni M, Qian ZR, Du J, Davis A, Mongare MM, Gould J, Frederick DT, et al. Tumour micro-environment elicits innate resistance to RAF inhibitors through HGF secretion. Nature. 2012;487(7408):500-4. 
14. Yu Y, Xiao CH, Tan LD, Wang QS, Li XQ, Feng YM. Cancer-associated fibroblasts induce epithelial-mesenchymal transition of breast cancer cells through paracrine TGF-beta signalling. Br J Cancer. 2014;110(3):724-32.

15. Elmusrati AA, Pilborough AE, Khurram SA, Lambert DW. Cancer-associated fibroblasts promote bone invasion in oral squamous cell carcinoma. $\mathrm{Br}$ J Cancer. 2017;117(6):867-75.

16. Ohlund D, Handly-Santana A, Biffi G, Elyada E, Almeida AS, Ponz-Sarvise M, Corbo V, Oni TE, Hearn SA, Lee EJ, et al. Distinct populations of inflammatory fibroblasts and myofibroblasts in pancreatic cancer. J Exp Med. 2017;214(3):579-96.

17. Costa A, Kieffer Y, Scholer-Dahirel A, Pelon F, Bourachot B, Cardon M, Sirven P, Magagna I, Fuhrmann L, Bernard C, et al. Fibroblast heterogeneity and immunosuppressive environment in human breast Cancer. Cancer Cell. 2018;33(3):463-79 e410.

18. Krtolica A, Parrinello S, Lockett S, Desprez PY, Campisi J. Senescent fibroblasts promote epithelial cell growth and tumorigenesis: a link between cancer and aging. Proc Natl Acad Sci U S A. 2001;98(21): $12072-7$.

19. Liu J, Xu K, Chase M, Ji Y, Logan JK, Buchsbaum RJ. Tiam1-regulated osteopontin in senescent fibroblasts contributes to the migration and invasion of associated epithelial cells. J Cell Sci. 2012;125(Pt 2):376-86.

20. Kim EK, Moon S, Kim DK, Zhang X, Kim J. CXCL1 induces senescence of cancer-associated fibroblasts via autocrine loops in oral squamous cell carcinoma. PLoS One. 2018;13(1):e0188847.

21. Biffi G, Oni TE, Spielman B, Hao Y, Elyada E, Park Y, Preall J, Tuveson DA. IL1induced JAK/STAT signaling is antagonized by TGFbeta to shape CAF heterogeneity in pancreatic ductal adenocarcinoma. Cancer Discov. 2019; 9(2):282-301.

22. Alexander J, Cukierman E. Stromal dynamic reciprocity in cancer: intricacies of fibroblastic-ECM interactions. Curr Opin Cell Biol. 2016:42:80-93.

23. Chan TS, Shaked Y, Tsai KK. Targeting the interplay between Cancer fibroblasts, Mesenchymal stem cells, and Cancer stem cells in Desmoplastic cancers. Front Oncol. 2019;9:688.

24. Kreizenbeck GM, Berger AJ, Subtil A, Rimm DL, Gould Rothberg BE. Prognostic significance of cadherin-based adhesion molecules in cutaneous malignant melanoma. Cancer Epidemiol Biomark Prev. 2008;17(4):949-58.

25. Yook JI, Li XY, Ota I, Hu C, Kim HS, Kim NH, Cha SY, Ryu JK, Choi YJ, Kim J, et al. A Wnt-Axin2-GSK3beta cascade regulates Snail1 activity in breast cancer cells. Nat Cell Biol. 2006;8(12):1398-406.

26. Batlle E, Sancho E, Franci C, Dominguez D, Monfar M, Baulida J, Garcia De Herreros A. The transcription factor snail is a repressor of E-cadherin gene expression in epithelial tumour cells. Nat Cell Biol. 2000;2(2):84-9.

27. Hemavathy K, Ashraf SI, Ip YT. Snail/slug family of repressors: slowly going into the fast lane of development and cancer. Gene. 2000:257(1):1-12

28. Hsu DS, Wang HJ, Tai SK, Chou CH, Hsieh CH, Chiu PH, Chen NJ, Yang MH. Acetylation of snail modulates the cytokinome of cancer cells to enhance the recruitment of macrophages. Cancer Cell. 2014;26(4):534-48.

29. Pelaez-Garcia A, Barderas R, Batlle R, Vinas-Castells R, Bartolome RA, Torres S, Mendes M, Lopez-Lucendo M, Mazzolini R, Bonilla F, et al. A proteomic analysis reveals that snail regulates the expression of the nuclear orphan receptor nuclear receptor subfamily 2 group F member 6 (Nr2f6) and interleukin 17 (IL-17) to inhibit adipocyte differentiation. Mol Cell Proteomics. 2015;14(2):303-15.

30. Hwang WL, Yang MH, Tsai ML, Lan HY, Su SH, Chang SC, Teng HW, Yang SH, Lan YT, Chiou SH et al: SNAIL regulates interleukin-8 expression, stem cell-like activity, and tumorigenicity of human colorectal carcinoma cells. Gastroenterology 2011, 141(1):279-291, 291 e271-275.

31. Yook Jl, Li XY, Ota I, Fearon ER, Weiss SJ. Wnt-dependent regulation of the E-cadherin repressor snail. J Biol Chem. 2005;280(12):11740-8.

32. Bae JY, Kim EK, Yang DH, Zhang X, Park YJ, Lee DY, Che CM, Kim J. Reciprocal interaction between carcinoma-associated fibroblasts and squamous carcinoma cells through interleukin-1alpha induces cancer progression. Neoplasia. 2014;16(11):928-38.

33. Bu L, Baba H, Yoshida N, Miyake K, Yasuda T, Uchihara T, Tan P, Ishimoto T. Biological heterogeneity and versatility of cancer-associated fibroblasts in the tumor microenvironment. Oncogene. 2019;38(25):4887-901.

34. Jin X, Liu D, Zhao X, Zhou Y, Jiang L, Li J, Zeng X, Chen Q. Analysis of clinicopathological characteristics associated with the outcome of ora squamous cell carcinoma and the establishment of tissue microarrays. Oncol Lett. 2016;12(5):3175-82.
35. Sloan P, Gale N, Hunter K, Lingen M, Nylander K, Reibel J, Salo T, Zain RB. Tumours of the oral cavity and mobile tongue. In: El-Naggar AK, JKC C, Grandis JR, Takata T, Slootweg PJ, editors. WHO classification of head and neck tumours. 4th ed. Lyon: International Agency for Research on Cancer; 2017. p. 109-11.

36. Lustig B, Jerchow $B$, Sachs $M$, Weiler S, Pietsch $T$, Karsten $U$, van de Wetering M, Clevers H, Schlag PM, Birchmeier W, et al. Negative feedback loop of Wnt signaling through upregulation of conductin/axin2 in colorectal and liver tumors. Mol Cell Biol. 2002;22(4):1184-93.

37. Wu ZQ, Brabletz T, Fearon E, Willis AL, Hu CY, Li XY, Weiss SJ. Canonical Wnt suppressor, Axin2, promotes colon carcinoma oncogenic activity. Proc Natl Acad Sci U S A. 2012;109(28):11312-7.

38. Zhang X, Kim KY, Zheng Z, Kim HS, Cha IH, Yook JI. Snail and Axin2 expression predict the malignant transformation of oral leukoplakia. Oral Oncol. 2017:73:48-55.

39. De Wever O, Demetter P, Mareel M, Bracke M. Stromal myofibroblasts are drivers of invasive cancer growth. Int J Cancer. 2008;123(10):2229-38.

40. Borsig L, Wolf MJ, Roblek M, Lorentzen A, Heikenwalder M. Inflammatory chemokines and metastasis--tracing the accessory. Oncogene. 2014;33(25): 3217-24.

41. Gales D, Clark C, Manne U, Samuel T. The chemokine CXCL8 in carcinogenesis and drug response. ISRN Oncol. 2013;2013:859154.

42. Aldinucci $D$, Colombatti A. The inflammatory chemokine CCL5 and cancer progression. Mediat Inflamm. 2014;2014:292376.

43. Soria G, Ben-Baruch A. The inflammatory chemokines CCL2 and CCL5 in breast cancer. Cancer Lett. 2008;267(2):271-85.

44. Watanabe $H$, Iwase M, Ohashi M, Nagumo M. Role of interleukin-8 secreted from human oral squamous cell carcinoma cell lines. Oral Oncol. 2002;38(7): 670-9.

45. Salcedo R, Ponce ML, Young HA, Wasserman K, Ward JM, Kleinman HK, Oppenheim JJ, Murphy WJ. Human endothelial cells express CCR2 and respond to MCP-1: direct role of MCP-1 in angiogenesis and tumor progression. Blood. 2000;96(1):34-40.

46. Stamatovic SM, Keep RF, Kunkel SL, Andjelkovic AV. Potential role of MCP-1 in endothelial cell tight junction 'opening': signaling via rho and rho kinase. J Cell Sci. 2003;116(Pt 22):4615-28.

47. Li A, Dubey S, Varney ML, Dave BJ, Singh RK. IL-8 directly enhanced endothelial cell survival, proliferation, and matrix metalloproteinases production and regulated angiogenesis. J Immunol. 2003;170(6):3369-76.

48. Heidemann J, Ogawa H, Dwinell MB, Rafiee P, Maaser C, Gockel HR, Otterson MF, Ota DM, Lugering N, Domschke W, et al. Angiogenic effects of interleukin 8 (CXCL8) in human intestinal microvascular endothelial cells are mediated by CXCR2. J Biol Chem. 2003;278(10):8508-15.

49. Buskermolen JK, Roffel S, Gibbs S. Stimulation of oral fibroblast chemokine receptors identifies CCR3 and CCR4 as potential wound healing targets. J Cell Physiol. 2017;232(11):2996-3005.

50. Xu M, Jiang H, Wang H, Liu J, Liu B, Guo Z. SB225002 inhibits prostate cancer invasion and attenuates the expression of BSP, OPN and MMP2. Oncol Rep. 2018;40(2):726-36.

51. Luca M, Huang S, Gershenwald JE, Singh RK, Reich R, Bar-Eli M. Expression of interleukin-8 by human melanoma cells up-regulates MMP-2 activity and increases tumor growth and metastasis. Am J Pathol. 1997;151(4):1105-13.

52. Pold M, Zhu LX, Sharma S, Burdick MD, Lin Y, Lee PP, Pold A, Luo J, Krysan K, Dohadwala M, et al. Cyclooxygenase-2-dependent expression of angiogenic CXC chemokines ENA-78/CXC ligand (CXCL) 5 and interleukin-8/CXCL8 in human non-small cell lung cancer. Cancer Res. 2004;64(5):1853-60

53. Freund A, Chauveau C, Brouillet JP, Lucas A, Lacroix M, Licznar A, Vignon F, Lazennec G. IL-8 expression and its possible relationship with estrogenreceptor-negative status of breast cancer cells. Oncogene. 2003;22(2):256-65.

54. Liu T, Zhou L, Li D, Andl T, Zhang Y. Cancer-associated fibroblasts build and secure the tumor microenvironment. Front Cell Dev Biol. 2019;7:60.

55. Bates AL, Pickup MW, Hallett MA, Dozier EA, Thomas S, Fingleton B. Stromal matrix metalloproteinase 2 regulates collagen expression and promotes the outgrowth of experimental metastases. J Pathol. 2015;235(5):773-83.

\section{Publisher's Note}

Springer Nature remains neutral with regard to jurisdictional claims in published maps and institutional affiliations. 